\title{
Architecture_MPS
}

\section{Affordable Housing: An Economic Perspective}

John F. McDonald ${ }^{1}$

How to cite: McDonald, J. F. 'Affordable Housing: An Economic Perspective.'

Architecture_MPS, 2015, 7(1): 3, pp. 1-16. DOI:

https://doi.org/10.14324/111.444.amps.2015v7i3.001.

Published: 01 May 2015

\section{Peer Review:}

This article has been peer reviewed through the journal's standard Editorial double blind peer review.

\section{Copyright:}

(C) 2015, The Author(s). This is an Open Access article distributed under the terms of the Creative Commons Attribution License (CC-BY) $3.0 \mathrm{https}: / /$ creativecommons.org/licenses/by/3.0/, which permits re-use, distribution and reproduction in any medium, provided the original author and source are credited・DOI: https://doi.org/10.14324/111.444.amps.2015v7i3.001

\section{Open Access:}

Architecture_MPS is a peer-reviewed open access journal. 


\title{
Title: Affordable Housing: An Economic Perspective
}

\author{
John F. McDonald
}

Architecture_media_politics_society. vol. 7, no.3.

May 2015

Affiliation: Emeritus Professor of Economics, University of Illinois at Chicago

\begin{abstract}
:
The economist's approach to social problems has two interrelated parts, consistent measurement and use of a cost-benefit test to assess alternative policies. This essay examines both parts of the economist's method, primarily in the context of the United States but with attention paid to the United Kingdom also. It will seek to demonstrate that the problem of affordable housing can be measured and is large, even in the U.S. Furthermore, it will suggest that the problem primarily is one of poverty., the alleviation of which, is a very long-run project. In this context, it will suggest that programs to improve the housing conditions of the poor in the meantime are justified.

Written by an economist, it will outline that economists favor a voucher program that subsidizes rents for poor households who rent in the private housing market and that they generally advocate preventing restrictions on housing supply and institutional change in nations that do not have well defined property rights. It will suggest that if poor households have purchasing power that is to be spent on housing and if a standard for acceptable housing is set, then the private market can respond. However, it will also argue that if the supply response from the private market is judged to be insufficient, then an increase in the value of the housing vouchers can be considered.
\end{abstract}




\title{
Title: Affordable Housing: An Economic Perspective
}

\author{
Author: John F. McDonald
}

\section{Architecture_media_politics_society.vol. 7, no.3.}

May 2015

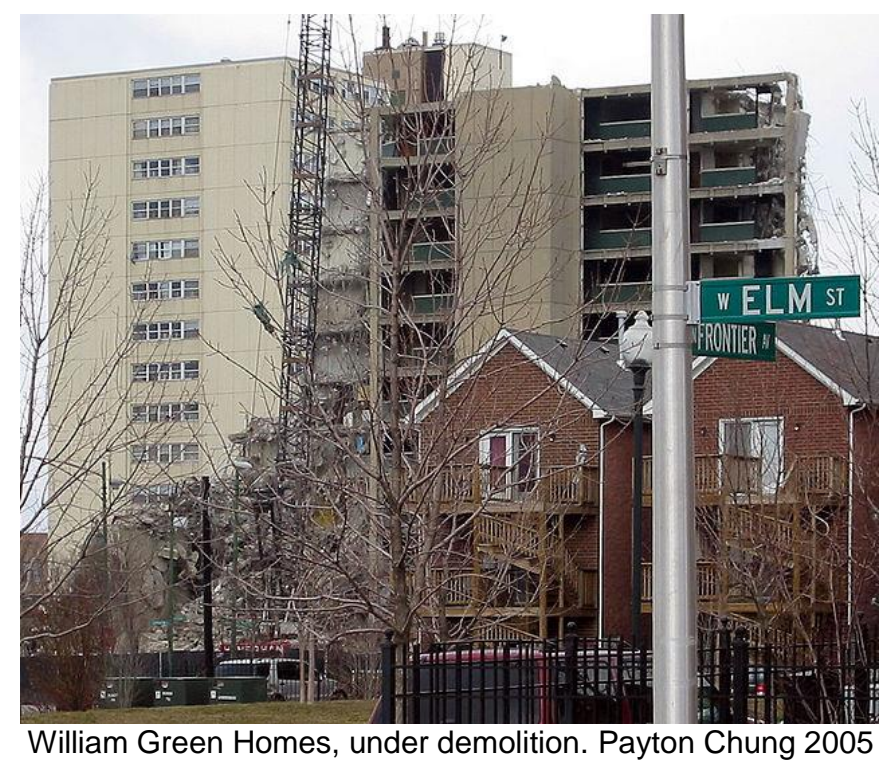

\section{Introduction}

The economist's approach to social problems has two interrelated parts, consistent measurement and use of a cost-benefit test to assess alternative policies. This essay examines both parts of the economist's method.

Economists (both liberal and conservative) think that the evidence to date shows that housing is most efficiently supplied in a competitive market in which the rights of property owners, landlords, and tenants are clearly stated in law and enforced in contracts. An important implication of this approach is that (in the absence of a general alleviation of poverty) the problem of affordable housing is most efficiently targeted by a housing voucher program in the United States that provides a rent subsidy for low-income households and also provides those households with some choice over their housing. ${ }^{1}$ The evidence is persuasive that poverty and the affordable housing program are closely linked, but the alleviation of poverty on a massive scale is a project for the very long run. In the meantime, society can use housing vouchers to improve the lives of the poor provided that property rights are well defined and enforced and the housing market is reasonably competitive. 


\section{Amps}

A serious question arises that western economists who study their own housing markets have not really considered. What if a nation does not have well defined property rights and/or lacks an effective housing market? And suppose that there is no real prospect that the nation can change the situation? How is such a nation to attack the affordable housing issue? This question should lead to serious efforts to find answers - which surely will vary depending upon the exact circumstances in a particular nation. Nevertheless, consistent measurement of the problem and use of cost-benefit analysis to assess alternative policies should still be on the agenda.

Modern economists are strong advocates for the measurement of the economy and the society. If the society has identified an economic or social problem, economists insist that one of the first steps is to conduct consistent measurements of the problem. Economists are responsible for creating the national economic accounts - gross domestic product, et al. The third Nobel Prize in economics was awarded to Simon Kuznets, who is regarded as the primary inventor of the system of national accounts in the 1930s. The Great Depression of the 1930s was, of course, the motivation behind the creation of national accounts and related measures such as the unemployment rate. Once it became clear that the prosperity of the U.S. in the 1950s was not reaching some people, economists designed the measurement of poverty that began with 1959. Since that time the measurement of poverty has spread to the rest of the world. None of the measurements in use is perfect, but they are essential in determining whether a problem is getting better or worse.

The social problem called "affordable housing" pertains to households with low incomes who cannot afford a minimally acceptable domicile except by spending a large percentage of their income. ${ }^{2}$ The size of the problem depends upon the definition of low income, the number of households below that threshold, the definition of minimally acceptable housing unit, the cost of such a unit, and the numerical standard for "large" percentage of income. The setting of these standards and the measurement of the relevant variables permit the society to measure the size of the affordable housing problem and to determine its trend over time. Measurement of a problem according to sensible standards that do not change is needed so that progress (or lack thereof) on reducing the problem can be reckoned. Some of this has been done in the U.S., so this paper includes a discussion of the affordable housing problem there. The American Housing Survey that is conducted in the U.S. includes measures of the lack of affordable housing for the nation and for individual metropolitan areas (and their central cities and suburban areas).

It is fair to say that the term affordable housing is not one that economists have been happy to use. Quigley and Raphael in a major article on the topic began by stating:

"But economists are wary, even uncomfortable, with the rhetoric of 'afforadability,' which jumbles together in a single term a number of disparate issues: the distribution of housing prices, the distribution of housing quality, the distribution of income, the ability of households to borrow, public policies affecting housing markets, conditions affecting the supply of new or refurbished housing, and the choices that people make about how much housing to consume relative to other goods." 3

In a similar vein, Green and Malpezzi stated that:

"Any such affordability calculation is, by its nature, arbitrary. It is based on some normative judgment about what households 'should' pay for housing. ...

Economists generally favor an alternative, positive definition of affordability. If households are observed to pay a given amount, then, from the economist's viewpoint, they can afford to do so. This is not a judgment about the desirability of any given payment, but simply an acknowledgement of its existence and of the household's revealed willingness to pay." 4 


\section{Amps}

But then Green and Malpezzi went on to say that:

"Which ever definition of 'affordability' one prefers, patterns and trends in housing expenditure relative to income are of intense interest. ... We do not adopt a normative standard of affordability, but just as more is preferred to less in terms of consumption, lower is preferred to higher in these affordability figures." 5

Quigley and Raphael took the same approach ${ }^{6}$.

Economists also insist that policies that aim to reduce identified social problems should be subject to an assessment of costs and benefits. Measurement systems should be designed to enable the assessment of costs and benefits. Measurement and cost-benefit analysis are two sides of the same coin. For example, economists have conducted numerous studies that show the inefficiency public housing programs for improving the housing conditions of low income households. A policy of providing a housing subsidy for low income households in the form of a voucher usually produces the same benefit for those households at a lower cost (or greater benefit for the same cost). It is fair to say that some policy advocates agree that social problems should be measured, but do not agree with the use of a cost-benefit test.

Public policy options include doing nothing. The use of the cost-benefit test is the same as requiring that using some public policy will be better than doing nothing. Here economists divide into more liberal and conservative camps. Liberal economists think the method of careful measurement and application of a cost-benefit standard can lead to effective public policy, and their research agenda often follows this path. It is fair to say that Quigley and Raphael ${ }^{7}$ as well as Green and Malpezzi ${ }^{8}$ are members of this group. In contrast, conservative economists think that, all too often, public policies are ill-timed, captured by special interest groups, or just plain wrong. Milton (winner of a Nobel Prize) and Rose Friedman are famous for asserting that ${ }^{9}$ :

"In the government sphere, as in the market, there seems to be an invisible hand, but it operates in precisely the opposite direction from Adam Smith's: an individual who intends only to serve the public interest by fostering government intervention is 'led by an invisible hand to promote' private interests, "which was no part of his intention."

The research agenda of the conservative economist often involves investigating how and why the Friedmans' invisible hand theorem was demonstrated in particular cases. George Stigler, another University of Chicago economist who won the Nobel Prize, founded the Chicago School of Political Economy that concentrates on taking a hard look at the motives for and results of particular public policies. One recent study by John Taylor shows that the aggressive policy of low interest rates pursued by the U.S. Federal Reserve during 2001-2004 was a primary cause of the housing market bubble, the collapse of which led to the financial crisis of $2008^{10}$. Taylor argues that the Federal Reserve instead should have followed a simple rule for setting interest rates.

To repeat, the economist's approach to social problems has two interrelated parts, consistent measurement and use of a cost-benefit test to assess alternative policies (including doing nothing). This essay examines both parts of the economist's method. Measurement falls short of being highly useful if it does not facilitate the analysis of policy, and policies cannot be assessed without measurement. Indeed, measurement itself might be subjected to a cost-benefit test. 


\section{Measurement of the Affordable Housing Problem}

As noted above, measurement of the affordable housing problem involves the following:

- Setting standards for low income,

- Measuring the number of households with low income,

- Defining the standards for a minimally acceptable housing unit,

- Measuring the cost of such a housing unit, and

- Setting a standard for the percentage of income spent on housing by low income households.

Each of these is discussed in turn.

The standard for low income can be in absolute or relative terms. In the U.S. the official poverty rate is based on absolute income, and varies with the size of the household. Studies of affordable housing sometimes use a figure of 0 to $30 \%$ of median household income for the low income group (an absolute measure). However, the measurement of the affordable housing problem sometimes is based on the bottom group in the distribution of household income (bottom 20\%, for example). Examples of both types of studies are discussed in some detail below.

Measurement of the number of households with low income requires periodic surveys of the households conducted in consistent fashion. The income that is measured in such surveys normally is current income from the previous year, but economists warn that the income for a particular year may not be an accurate measure of the ability of a household to pay for housing. Starting with Friedman (Friedman 1957), economists prefer the notion of permanent income, an average of income over a period of years, because this income is the more relevant concept when it comes to making the longerterm decision regarding housing ${ }^{11}$. It is quite possible that some households are found to be spending a large percentage of current income on housing because of a temporary income dip, but that the percentage in the longer run is lower. The fact that household surveys such as the census, current population survey, and American Housing Survey do not include measures of permanent income renders measurement imperfect, but not useless. Another measurement issue is the definition of the forms of income that should be included. Should government benefits in the form of cash (i.e., transfer payments) be included? Should in-kind government benefits (e.g., health care) be included? Should gifts (monetary and in kind) be included?

Defining standards for a minimally acceptable housing unit is a complex matter. First, local governments impose building codes and housing codes so as to protect the health and welfare of the public. Indeed, these codes, which vary from place to place, provide standards for the minimally acceptable housing unit. However, building codes and housing codes sometimes (often?) are influenced by special interests such as construction companies, construction workers, and local property owners with the result that the codes go beyond basic protection of the public. Second, while building codes as they pertain to newly constructed housing normally are enforced, housing codes that pertain to existing units may not be enforced with much rigor in some locations (e.g., slum housing owned by slumlords).

Given that local building and housing codes and their enforcement vary from place to place, measurement of the affordable housing problem may be facilitated by a national standard for the minimally acceptable housing unit. That standard may vary with a short list of variables, such as household size and urban or rural location. The standard should meet with general agreement in the society, but from the economist's perspective of measurement there is some leeway in this definition. Use of a sensible standard applied consistently over time is needed for measurement. 


\section{Amps}

Another difficulty is that the standard that society would set for a minimally acceptable housing unit changes over time. At one time outhouses were acceptable in the U.S., even though indoor plumbing was available (for a price). Outhouses are acceptable no longer. Single-room occupancy hotels with a communal bathroom down the hall were acceptable according to local housing codes, but now are prohibited by many local codes.

Consider the national standards that have been set by the U.S. Department of Housing and Urban Development (HUD). See Steffen (Steffen 2103). In 1974 HUD set standards for severe inadequacy of a housing unit ${ }^{12}$. A unit is severely inadequate if any of the following criteria apply.

- Unit does not have flush toilet, or bathtub or shower, or does not have hot and cold running water, or shares plumbing facilities.

- Unit has inadequate heating.

- Electricity is not used.

- Unit has inadequate wiring and electrical plugs.

- Unit has five of the six following upkeep problems:
a. Outside water leaks.
b. Inside water leaks.
c. Holes in floor.
d. Open cracks wider than a dime.
e. Peeling paint.
f. Rats seen in unit.
g.

As of 2011 only $3.1 \%$ of rental units in the U.S. were severely inadequate (up from $2.8 \%$ in 2009 ).

HUD also has a set of standards for moderately inadequate housing as follows. A unit is moderately inadequate if it has none of the severe problems and has any of the following problems.

- All toilets break down simultaneously.

- Unit has unvented gas, oil, or kerosene heaters as main source of heat.

- Unit has three of the six upkeep problems associated with severe inadequacy.

- Unit lacks a sink, range, or refrigerator (i.e., food preparation equipment) for exclusive use.

Also, a moderately severe problem exists if the unit has more than one resident per room.

In short, a unit is adequate if it has a full bathroom (with a toilet that breaks down infrequently), has a kitchen, has vented heating, has fewer than three upkeep problems, and is not crowded. Note that a unit can be considered to be adequate if a rat has been seen in the unit or has holes in the floor, etc.

The largest housing subsidy program for low-income households in the U.S. is a housing voucher program in which the household pays a rent equal to $30 \%$ of its income and the federal government (through a local housing authority) pays the additional fair market rent. It is reasonable that the government does not pay rent for bad housing. But just what sort of housing is the government willing to include in the program? The standards are higher than the criteria for adequate housing listed above. The housing units must, of course, satisfy the local building and housing codes for safety and structural integrity and so on, and in addition the units must satisfy the federal criteria listed in Table 1. Some of those criteria repeat local requirements (as noted), but others go beyond local code requirements. A private bathroom with toilet, bath tub or shower, and sink is required - as most local codes also stipulate. $^{13}$ However, the HUD requirements for food preparation include an oven and stove (hot plates prohibited) and refrigerator that is large enough for the household. These requirements go beyond those included in many local housing codes. 
The numbers of units that meet the HUD standards for severely inadequate and moderately inadequate have been measured for the nation. The figures for 2009 and 2011 are as follows (1000s).

$\begin{array}{lrr} & 2009 & 2011 \\ \text { Total rental units } & 35,396 & 38,867 \\ \text { Severely inadequate units } & 998 & 1,072 \\ \text { Moderately inadequate units } & 1,684 & 1,830\end{array}$

Source: Steffen (2013) for U.S. Dept. of HUD.

Other researchers have used short-cuts in their attempts to measure the problem. For example, Quigley and Raphael tabulated the percentage of rental units with rents less than $30 \%$ of the median income of the bottom $20 \%$ of renter households ${ }^{14}$. As it happened, in 2000 only $7 \%$ of rental units in the U.S. had rents less than $30 \%$ of the median income of this group at the bottom of the income distribution, but that $32 \%$ of renter households were in this bottom group.

How is the cost of a minimally acceptable housing unit measured? Clearly that cost varies from place to place. HUD establishes fair market rent for the housing voucher program by location. They do a survey of local rents, and set fair market rent at the $40^{\text {th }}$ percentile of the distribution of market rents. Fair market rent also varies with the size of the unit (based on the number of bedrooms). HUD pays the landlord the difference between fair market rent for the unit and 30\% of the household's income from the most recent time period. In short, HUD does not attempt to measure the rent of the acceptable unit as defined in Table 1, but rather assumes that rent at the $40^{\text {th }}$ percentile of the rent distribution is consistent with those standards. I know of no other general systematic effort in the U.S. to measure the rent of the minimally acceptable housing unit.

Table 1

Housing Standards for Housing Choice Vouchers in the U.S.

Sanitary Facilities

Food Preparation

Space \& security

Thermal environment

Illumination \& electricity

Structure \& materials Interior air quality

Water supply
Bathroom with flush toilet, sink, hot \& cold water

Tub or shower

Privacy

Oven and stove (not hot plate)

Refrigerator large enough for household

Sink, hot \& cold water

Storage space

Living room, kitchen \& bathroom

One bedroom for every 2 persons

Lockable doors \& windows

Heat to 65 degrees (no space heater)

Furnace vented

Window in living room and bedrooms

Light fixture in bath and kitchen

Two outlets in bedroom and living room

Structurally sound \& maintained

Free of air pollutants, adequate ventilation

Bathroom has window or ventilation

Windows not painted or nailed shut

Free of contamination

Water leaves unit free of sewer gas or backups 
Lead-based paint

Access

Site \& neighborhood

Sanitary condition

Smoke detectors
If child under 6 might occupy unit, rules apply

Private access

Alternate fire exit (unblocked)

Free of dangers to health, safety \& general welfare

(e.g., flooding, noise, traffic)

"Bad" neighborhood not reason to fail*

Free of vermin, rodents, trash

Conform to local requirements

*Takes into account whether private unassisted residents live in the same neighborhood. [end of Table 1]

Housing markets are local, and rents vary from place to place. The number of units that are affordable to lower-income households depends upon the market - the supply and demand for housing. On the supply side, much of the housing occupied by lower-income households is older housing. Housing economists use what is called the filtering model to understand the operation of the housing market in a metropolitan area. Malpezzi and Green is a good example of a study based on the filtering model ${ }^{15}$. Housing units can be arrayed according to quality - from top to bottom. Most new housing adds to the stock of housing above average in quality, and accommodates an increase in the number of households. However, if the construction of new housing exceeds the growth in the number of households, then some households can move up in the housing quality array. A chain of moves can occur that results in an improvement in housing quality for some households at the bottom of the quality array. Some of the worst housing units become vacant and eventually are removed from the stock, and some lowerincome households occupy better housing at rents that are no higher than before. Research on housing market dynamics by Malpezzi and Green has shown that the quality of the housing stock available to lower-income households depends upon the construction of new housing at any and all levels of quality ${ }^{16}$. Metro areas that restrict new construction have higher rents for housing at the bottom of the quality array, and metro areas with unrestricted supply conditions have lower rents at the bottom. Indeed, as discussed in detail by Quigley and Raphael, in recent years housing economists have demonstrated the harmful effects of a wide variety of measures that restrict housing supply ${ }^{17}$.

The last step in the measurement of the affordable housing problem is setting the percentage of income spent on housing that is consistent with affordability. In the U.S. the standard (used by HUD and by researchers) is 30\%. Obviously this is an arbitrary, but not unreasonable, standard. However, researchers also track the problem using $50 \%$ of income as the standard.

So let us see how the HUD system for measuring the extent of the affordable housing problem works. The American Housing Survey (AHS) is done in alternate years on a nation-wide basis (with larger sampling of a changing select group of metro areas). The AHS includes all of the variables needed to produce alternative measures of the affordable housing problem. Household income includes government transfer payments and, in particular, questions are included that provide estimates of the numbers of units severely inadequate and moderately inadequate. The results for 2011 are displayed in Table 2.

A household is considered to have a severe problem if rent exceeds $50 \%$ of income or if the housing unit is severely inadequate. A household has a non-severe problem if rent falls between $30 \%$ and $50 \%$ of income or if the unit is moderately inadequate or crowded. Data are provided for households by income range. The bottom group had an income of 0 to $30 \%$ of the median household income for the metro area. The income level at $30 \%$ of median is about $\$ 15,000$ per year. The next group up had an income of $30 \%$ to $50 \%$ of the median for the metro area, and so on. 


\section{Amps}

Note some basic facts about rental housing in the U.S. in 2011. There were an estimated total of 38.867 million renter households, and that 5.298 million participated in some form of subsidized housing (public housing or subsidized private housing). Renter households in the bottom income group numbered 11.774 million (30.3\% of all renter households, and 3.648 million of these households $(31.0 \%)$ lived in subsidized housing.

\section{Table 2}

Housing Conditions of Renter Households by Relative Income, 2011

\begin{tabular}{|l|r|r|r|r|r|r|}
\hline & $0-30 \%$ & $30-50 \%$ & $50-80 \%$ & $80-120 \%$ & $>120 \%$ & All Incomes \\
\hline Total households & 11,774 & 7,492 & 7,750 & 5,799 & 6,051 & 38,867 \\
Assisted* & 3,648 & 943 & 403 & 196 & 108 & 5,298 \\
Unassisted & & & & & & \\
Severe problems & 6,209 & 2,266 & 683 & 210 & 180 & 9,548 \\
Nonsevere problems & 934 & 3,264 & 3,218 & 1,174 & 604 & 9,194 \\
No problems & 984 & 1,019 & 3,447 & 4.218 & 5,159 & 14,828 \\
\hline Any w/ severe problem & 7,716 & 2,386 & 712 & 226 & 181 & 11,220 \\
Rent > 50\% income & 7,534 & 2,196 & 494 & 98 & 68 & 10,391 \\
Severely inadeq. Unit & 479 & 256 & 226 & 130 & 114 & 1,204 \\
\hline Any w/ nonsevere prob. & 2,022 & 3,682 & 3,380 & 1,199 & 612 & 10,895 \\
Rent 30-50\% income & 1,663 & 3,465 & 2,880 & 830 & 287 & 9,124 \\
Moderate inadeq. unit & 443 & 403 & 417 & 299 & 268 & 1,830 \\
Crowded unit & 220 & 350 & 300 & 117 & 85 & 1,072 \\
\hline Any w/ no problems & 2,037 & 1,424 & 3,659 & 4,374 & 5,259 & 16,753 \\
\hline
\end{tabular}

*Assisted means unit is public housing or subsidized private housing.

Source: Steffen (2013) for U.S. Dept. of HUD.

Table 2 makes it clear that the affordable housing problem primarily is one of rent burden, and not one of severely inadequate housing. As noted above, 3.1\% (1.204 million) of rental units were severely inadequate. The bottom income group occupied 0.479 million $(39.8 \%)$ of those units. In contrast, the rent burden was greater than $50 \%$ of income for 10.391 million households. The bottom income group included 7.534 million households with a rent burden greater than $50 \%$ of income, which is $64.0 \%$ of the 11.774 million households in this group. ${ }^{18}$ In addition, 1.663 million households in the bottom income group had rents that were $30 \%$ to $50 \%$ of income. So, if one uses the $30 \%$ as the standard, $78.1 \%$ of the lowest income group had rents greater than $30 \%$ of income. Just $7.8 \%$ ( 0.922 million) of households in the lowest income group occupied housing units that were severely inadequate or moderately inadequate.

The affordable housing problem faced by the next group higher on the income scale (30\% to 50\% of median income) was much less pronounced, but still sizable. Rent burden greater than $50 \%$ of income was found for $29.3 \%$ of this group, and $46.2 \%$ of the group had rents of $30 \%$ to $50 \%$ of income. Some households with income above the median had high rent burdens as well, but one might regard high rents for these groups as a choice, and not a social problem.

The basic message in Table 2 is that the affordable rental housing problem in the U.S. largely is a problem of the percentage of household income spent on rent. Severely inadequate housing in the U.S. essentially is defined as units without a complete private bathroom or no electricity (or serious structural or equipment failures), but only a small percentage of rental units is severely inadequate. 


\section{Amps}

Table 2 shows us that, if we insist that each household in the U.S. "should" have a complete private bathroom and electricity, then the problem of affordable housing very largely is one of poverty.

The Joint Center for Housing Studies of Harvard University produces annual reports on the state of the nation's housing ${ }^{19}$. Severe housing cost burden is regarded as rent more than $50 \%$ of household income (including transfer payments, corrected for inflation). Given that there are relatively few severely inadequate rental housing, tracking rent burden over time is a valid approach. The percentage of rental households in the lowest income group (less than $\$ 15,000$ ) with a severe cost burden (greater than 50\%) increased from $66.5 \%$ in 2001 to $71.4 \%$ in 2011, and most of that increase took place after the recession and financial crisis that began in 2007. The percentage of renter households in the nexthigher income group ( $\$ 15 \mathrm{~K}$ to $\$ 30 \mathrm{~K}$ ) that paid more than $50 \%$ in rent increased as well. Both of these income groups are substantial fractions of the total population of rental households; $21 \%$ in 2001 and $25 \%$ in 2011 for the lowest income group and 22\% in 2001 and $24 \%$ in 2011 for the next-highest group. Renter households in 2001 were 36.5 million in 2001 and 40.6 million in 2011.

\section{Analysis of the Affordable Housing Problem}

Analysis of affordable housing data takes two forms. One type of studies examines the changes in the size and nature of the affordable housing problem and looks for the variables that are associated statistically with those changes. The affordable housing problem got worse because rents went up (or incomes went down). What was behind the increase in rents (or declines in income)? Quigley and Raphael is a good example of a study of this type ${ }^{20}$. The other type of study examines the impacts of policies aimed at the affordable housing problem. Policy analysis has two varieties - studies based on social experiments or quasi experiments, and studies based on economic models of the housing market. Analysis can be conducted at the national level, or at lower levels of geography such as the metropolitan area.

Real social experiments are expensive and rarely conducted. The most famous are the Housing Allowance Experiments of the 1970s. One part of the experiments examined what would happen if all eligible households in a medium-sized housing market were given the opportunity to receive housing vouchers. The basic outcome is that there was minimal impact on market rents and housing prices. The other part of the experiment tested the impact of housing subsidies on housing consumption. Households took the opportunity to spend more of their own income on other goods. A reduction in rent mainly enabled households to save their own money on housing so that other goods and services could be purchased, although a small improvement in housing quality was also observed. See Friedman and Weinberg ${ }^{21}$ (Friedman and Weinberg 1982) for a presentation of the results of these experiments. Quasi experiments are instances when a change in the housing market takes place that is completely exogenous to the market. The idea is to find times when an exogenous force has an impact on the market that permits a "clean" study of how the market behaves. The goal is to identify the true effects of the change not confounded by other factors. I know of no study of affordable housing based on a quasi experiment. Studies of this kind are needed.

The other type of policy study uses structured economic models that are constructed based on basic economic principles. Empirical estimates of critical model parameters must be included. For example, households are assumed to be rational maximizers of utility, and various empirical studies have shown that the income elasticity of demand for housing is 0.4 and the price elasticity of demand is $-0.3 .^{22}$ Given this model, we can estimate the impact of various types of housing subsidies or income supplements. The model can be used to compute the change in housing consumed for a given expenditure on a particular policy option, and then to compare the various policy options. The advantage of using a structured economic model is that a wide variety of policy options can be tested. 


\section{Amps}

The study by Mayo (Mayo 1986) is a good example of this approach in which he compares public housing, a construction subsidy program, a rent subsidy program to support new construction or substantial rehabilitation of units, and two forms of housing vouchers ${ }^{23}$. The more accurate is the model, the more accurate is the analysis, of course.

Green and Malpezzi reviewed the studies of various housing subsidy programs in the U.S., and found that public housing is inferior to housing vouchers in the ability to deliver benefits compared to $\operatorname{costs}^{24}$. Public housing was found to be produced inefficiently compared to private housing, and found to provide lower benefits to households. Production inefficiency arises from a variety of causes inappropriate locations, poor design, high labor and administrative costs, higher maintenance costs, tax breaks, and so on. All of these problems reflect a lack of market discipline. Public housing also means that resident household choices are constrained by the nature of the housing in the program. Cash transfers are the most efficient subsidy in that recipients buy only those items that are worth at least as much as they cost. With public housing households are provided with a low rent (30\% of income), but must take the public housing unit offered - or not be subsidized at all. Housing vouchers in fact had better production efficiency and consumer benefits.

\section{Affordable Housing Policies}

This section is a brief survey of polices that have been used to attack the problem of affordable housing. The focus is on rental housing in countries with markets for housing.

\section{Rent Control}

Rent control programs exist all over the world. McDonald and McMillen provide a brief survey of rent control programs around the world ${ }^{25}$. Rent control around the world takes many forms, but most fall into one of the following categories:

- Tenancy rent control in which initial rent is set freely, but subsequent increases for the same tenant are fixed or keyed to some cost index. Base rent is reset when a new tenant moves in.

- Maximum rent systems in which the maximum rent applies to all tenants. The rent is set according to some rule (e.g., percentage of initial property value). The rent does not change over time, so the real value of the rent falls with general inflation.

- Split systems in which rents are controlled only for low-income households or units that have been converted from public to private ownership.

Is rent control an effective means for attacking the problem of a lack of affordable

housing? Tenancy rent control and maximum rent systems as defined above control rents for all tenants (including low-income tenants), but obviously are not targeted to the affordable housing problem. General rent control of either form meets with harsh criticisms by economists. As discussed by Arnott, most economists agree that these old-fashioned forms of rent control discourage new construction, reduce maintenance and household mobility, cause rental units to be converted to owneroccupied housing, and stimulate black markets ${ }^{26}$. For example, tenancy rent control gives the tenant an incentive to remain in the unit even as its circumstances change (e.g., income and household size) because movement to another unit will mean that rent will be updated. Some economists such as Arnott advocate a newer form of rent control that mitigates some of these problems ${ }^{27}$. This type would exempt new construction entirely, permit rent adjustments based on inflation or verifiable increases in expenses, and include requirements for maintenance. Split systems of rent control can be targeted to low-income households, but the general problems with rent control remain. In short, most economists take a dim view of rent control programs as they actually exist. 


\section{Public Housing}

Public housing exists in many countries. This brief discussion examines just two of those programs.

The United Kingdom began its program of Council Housing in earnest with the Housing Act of 1919. McDonald and McMillen ${ }^{28}$ (McDonald and McMillen 2011) provide a brief history. Local housing councils built housing with the assistance of funds from the central government, and the units were rented to local residents at subsidized rents. The Council Housing program went through several versions; slum clearance in the 1930s, New Towns after World War II, high rise buildings in the 1950s (mostly demolished in the 1980s because of maintenance and repair problems), and the transfer of many units to private housing associations after 1979. The right-to-buy program instituted after 1979 transferred ownership of some units to the tenants. But Council Housing still is a major portion of the rental housing market. The 2001 Census of England and Wales, as cited in McDonald and McMillen shows that, as of $200143 \%$ of all rental housing in the UK is Council Housing and $19 \%$ is rented from private housing associations ${ }^{29}$. The rate of home ownership in the UK is $69 \%$, which is comparable to the rate in the U.S. Critics of Council Housing pointed out that it impedes household mobility because tenants did not lose eligibility as long as they pay rent on time, and because a household that moves to another jurisdiction was put at the bottom of the waiting list.

The federal public housing program in the U.S. began in 1937, and by 1967 just 633,000 units had been built (with 41,000 units under construction). There is an extensive literature on the history of this program. See McDonald ${ }^{30}$ (McDonald 2013) for a brief overview of the history of public housing up through 1967 and a study of the factors related to the number of units constructed in the major cities as of that date. Local housing authorities prepared proposals to the federal program and received subsidies for the approved proposals. The cities of New York and Chicago were the largest suppliers of public housing. Many of the units built in the 1950s and 1960s were in high-rise buildings, and a large number of these "projects" were badly designed and poorly managed. The buildings became dominated by very poor households, and the concentration of poverty has been shown to exacerbate the social problems of the poor. Most of these buildings have now been demolished. Hunt provides a detailed history of the failed public housing program in Chicago ${ }^{31}$.

The programs in the UK and the U.S. have demonstrated that public housing in high-rise buildings is a bad idea, especially if those buildings are not well designed, poorly maintained, and dominated by very poor households. Is it possible to have a public housing program that differs from this dismal picture? The answer is "yes." Low-rise public housing (as much of Council Housing was) is far more successful. In the U.S. public housing units are now being developed as part of private mixed-income developments that use a variety of funding sources, including the Low Income Housing Tax Credit (LIHTC) program. The federal government allocates a certain amount of these tax credits to each state, and a state agency allocates the credits to approved projects. The tax credits are sold on the open market, and the funds generated become equity in the housing development. The developer is required to offer a certain percentage of units to low-income households at subsidized rents, and offers the other units at market rents. This program has become the main source of affordable housing development in the U.S. However, since the units are designed for the private market and all units must be of equal quality, the cost of the public housing units is very high. Indeed, the research reviewed by Green and Malpezzi showed that standard public housing is a relatively inefficient method for supplying affordable housing ${ }^{32}$. The public housing supplied under the LIHTC program likely is even less efficient. An early study of the LIHTC program by ICF Incorporated concluded that one dollar of tax credit raised tenant welfare by 53 cents while one dollar of housing voucher raised tenant welfare by 96 cents. 


\section{Amps}

A fundamental problem with the public housing program is that the demand for units far exceeds the supply. A more efficient policy could at least provide benefits to more low-income households for the same total cost.

The record of housing construction in formerly communist nations sometimes produced a peculiar (and inefficient) outcome. For example, Moscow was developed by central planners with no reference to land prices, which did not exist in the communist era. The result is that the population density in the Moscow metro area increases with distance to the central area. Taller and taller apartment buildings were built over time on the available land at the existing fringe of the urban area. In complete contrast, population density declines with distance to the central area in all urban areas with active land markets because employment is concentrated at the center. Workers in Moscow would have shorter commutes if market forces had been permitted to operate. See McDonald and McMillen for a chart showing the inverted population density pattern for Moscow and negatively-sloped population graphs for several other cities around the world with land markets ${ }^{33}$.

\section{Loosen Restrictions on Housing Supply}

A substantial body of research shows that localities with greater restrictions on housing supply have higher housing prices and rents and therefore greater affordable housing problems. Studies such as Malpezzi and Green's have shown that making it easier to build any type of housing will increase the supply of lower-cost housing ${ }^{34}$. What are the existing restrictions on supply? Quigley and Raphael (2004) believe that the most extreme form of supply restriction is an explicit growth control such as a moratorium on new developments, urban growth boundaries, and open space requirements aimed at preserving undeveloped land. Municipal zoning, building, and housing codes also can have the effect of restricting supply. Zoning provisions that restrict housing supply include "large lot" zoning (aimed at reducing density and controlling the demand for pubic services) and zoning large amounts of land for commercial use that will generate tax revenue and require little in public services. The general term for rules of this type is "fiscal zoning." Malpezzi and Mayo found that developing countries (e.g., Malaysia and South Korea) with highly restrictive land use and redevelopment regulations inhibit housing quality improvements as economic development proceeds ${ }^{35}$.

The policy recommendation is to loosen the restrictions on housing supply in general. Local governments cannot be expected to pursue such a course on their own because their fiscal incentives are in the opposite direction, so action at a higher level of government such as the state level is needed. However, once enacted, rules that restrict supply are difficult to eliminate. A complementary suggestion is to organize opposition to restrictive rules before they are enacted. State or national laws that prohibit certain forms of growth controls and fiscal zoning can be proposed.

\section{Housing Vouchers}

Housing vouchers first were introduced in the U.S. in 1974, and have become the primary affordable housing program. The program and the research supporting the concept were described in some detail above. Housing economists have been advocating voucher programs for many years. Public housing advocates such as Bennett, Smith and Wright argue that the program depends upon appropriations by the U.S. Congress, and that those funds can be cut at any time ${ }^{36}$. So they argue that public housing units should be built because they cannot be eliminated (at least in the short run). It is true that the supply of housing vouchers is determined by Congress, and that the demand far exceeds the supply. See Table 2 above. But the same was true for public housing, which is less efficient.

\section{Informal Housing}

Informal housing is not a program, of course. Rather it is the default outcome for many households in developing countries. Informal housing is housing of poor quality that is below a socially desirable 


\section{Amps}

standard, such as the favelas of Brazil, and that is not counted as part of the "official" housing stock. A study by Annez and Wheaton ${ }^{37}$ (Annez and Wheaton 1984) documented the size of the informal housing market in 24 countries for 1960 and 1970. They collected official data on housing production (permits and starts) and housing units recorded in the census from 1960 to 1970. If all units had been recorded in the official data, the ratio of recorded units to the change in the housing stock should exceed 1.0 because of removals of units. However, the ratio of recorded production to the change in the housing stock for various developing countries ranged from 0.14 in the Philippines to 0.72 in Syria. Such figures give a rough idea of the magnitude of the affordable housing problem in developing countries (at least during the 1960s). The ratios in advanced countries such as France, Germany, Japan, UK and the U.S. exceeded 1.0.

Annez and Wheaton studied the factors that were related to the change in the housing stock and found in essence that growth in GNP per household improves housing quality (i.e., a greater percentage of recorded units) and increases the size of recorded units only by a small amount ${ }^{38}$. In short, the problem of affordable housing responds to economic growth unless, as shown in the Malpezzi and Green study noted above, the nation imposes restrictions on housing supply ${ }^{39}$.

\section{Conclusion}

This paper has served to demonstrate that the problem of affordable housing can be measured and is large, even in the U.S. Furthermore, the problem primarily is one of poverty. The alleviation of poverty reduces the ratio of rent to income in a developed nation such as the U.S. and reduces the reliance on informal housing in developing countries. However, it is fair to say that no nation has a system of measuring the problem of affordable housing that is linked to the policies designed to mitigate the problem. In addition, more cost-benefit studies of affordable housing policies are needed.

The alleviation of poverty is a very long-run project, so programs to improve the housing conditions of the poor in the meantime are justified. Economists favor a voucher program that subsidizes rents for poor households who rent in the private housing market, provided that the market is competitive and has well defined property rights. They advocate preventing restrictions on housing supply and institutional change in nations that do not have well defined property rights. If poor households have purchasing power that is to be spent on housing and if a standard for acceptable housing is set, then the private market can respond. If the supply response from the private market is judged to be insufficient, then an increase in the value of the housing vouchers can be considered.

\footnotetext{
${ }^{1}$ Housing vouchers in the U.S. are granted to households with low incomes. The household pay rent equal to $30 \%$ of monthly income. The land lord receives rent based on actual market rent, and the difference between the rent paid by the household and the market rent is paid by the government. Rental units in the program must meet certain standards, which are discussed below.

${ }^{2}$ In the U.S. housing affordability for households with higher incomes primarily pertains to the cost of owning a home. Of course, this topic has generated a great deal of debate, public policy, and research. But for purposes of this paper the more pressing social problem is rental housing for low-income households. See Quigley and Raphael (2004) for documentation.

${ }^{3}$ John Quigley and Stephen Raphael. "Is Housing Unaffordable? Why Isn't It More Affordable?" The Journal of Economic Perspectives 18 (2004): 191-192.

${ }^{4}$ Richard Green and Stephen Malpezzi. A Primer on U.S. Housing Markets and Housing Policy (Washington, DC: Urban Institute Press, 2003) 135-136

${ }^{5}$ Green and Malpezzi, "A Primer on U.S. Housing Markets," 136-137.

${ }^{6}$ Quigley and Raphael, "Is Housing Unaffordable? ”, 191-192.

${ }^{7}$ Ibid.

${ }^{8}$ Green and Malpezzi, "A Primer on U.S. Housing Markets."

${ }^{9}$ Milton Friedman and Rose D. Friedman, Free to Choose (New York: Harcourt Brace Jovanovich, 1980), xix.
} 
${ }^{10}$ John Taylor, Getting Off Track: How Government Actions and Interventions Caused, Prolonged, and Worsened the Financial Crisis (Stanford, CA: Hoover Institution Press, 2009).

${ }^{11}$ Milton Friedman, A Theory of the Consumption Function (Princeton, NJ: Princeton University Press 1957).

12 Barry Steffen, "Worst Case Housing Needs 2011." (Report to Congress, U.S. Dept. of Housing and Urban Development, 2013).

${ }^{13}$ However, the City of Chicago housing code permits the sharing of a bathroom by two small one-person housing units.

${ }^{14}$ Quigley and Raphael, "Is Housing Unaffordable?

15 Stephen Malpezzi, and Stephen Mayo. 1997 “Getting Housing Incentives Right: A Case Study of the Effects of

Regulations, Taxes, and Subsidies in Housing Supply in Malaysia.” Land Economics 73 (1997): 372-391.

16 Ibid.

${ }^{17}$ Quigley and Raphael, "Is Housing Unaffordable?

${ }^{18}$ Note that some households in the lowest income groups occupied subsidized housing units, but still paid rents greater than $50 \%$ (or $30 \%$ to $50 \%$ ) of income.

${ }^{19}$ Joint Center for Housing Studies of Harvard University. "The State of the Nation's Housing." (Cambridge: Harvard University, 2013).

${ }^{20}$ Quigley and Raphael, "Is Housing Unaffordable?

${ }^{21}$ Joseph Friedman, and Daniel Weinberg, The Economics of Housing Vouchers (New York: Academic Press, 1982).

${ }^{22}$ Price elasticity of demand is the percentage change in quantity purchased divided by the percentage change in the price of the good.

${ }^{23}$ Stephen Mayo, "Sources of Inefficiency in Subsidized Housing Programs: A Comparison of U.S. and German

Experience," Journal of Urban Economics 20 (1986): 229-249.

${ }^{24}$ Richard Green and Stephen Malpezzi, A Primer on U.S. Housing Markets and Housing Policy (Washington, DC: Urban Institute Press, 2003).

${ }^{25}$ John F. McDonald, and Daniel P. McMillen, Urban Economics and Real Estate: Theory and Policy, (Hoboken, NJ: John Wiley \& Sons, 2011), 228-231.

${ }^{26}$ Richard Arnott, "Time for Revision on Rent Control?" Journal of Economic Perspectives 9 (1995): 99-120.

27 Ibid.

${ }^{28}$ McDonald, and McMillen, "Urban Economics."

${ }^{29}$ Ibid.

${ }^{30}$ John McDonald, "Public Housing Construction and the Cities: 1937-1967," Urban Studies Research (2011): 1-12.

${ }^{31}$ D. Bradford Hunt, Blueprint for Disaster: The Unraveling of Chicago Public Housing ( Chicago: University of Chicago Press, 2009).

${ }^{32}$ Green and Malpezzi, "A Primer on U.S. Housing Markets."

${ }^{33}$ McDonald, and McMillen. "Urban Economics, "120-133

${ }^{34}$ Stephen Malpezzi, and Richard Green, "What Has Happened to the Bottom of the U.S. Housing Market?" Urban Studies 33 (1996) : 1807-1820.

${ }^{35}$ Stephen Malpezzi and Stephen Mayo. "Getting Housing Incentives Right: A Case Study of the Effects of Regulations, Taxes, and Subsidies in Housing Supply in Malaysia," Land Economics 73 (1997): 372-391.

${ }^{36}$ Larry Bennett, Janet Smith, and Patricia Wright. Where Are the Poor to Live?: Transforming Public Housing Communities (New York: M.E. Sharpe, 2006).

${ }^{37}$ Phillipe Annez and William Wheaton, "Economic Development and the Housing Sector: A Cross-National Model,” Economic Development and Cultural Change 32 (1984): 749-766.

38 Ibid.

${ }^{39}$ Malpezzi and Green, "What Has Happened". 


\section{Bibliography}

Annez, Phillipe,, and William Wheaton. "Economic Development and the Housing

Sector: A Cross-National Model," Economic Development and Cultural Change 32 (1984) : 749-766.

Arnott, Richard. "Time for Revision on Rent Control?" Journal of Economic

Perspectives 9 (1995) : 99-120.

Bennett, Larry, Smith, Janet and Patricia Wright. Where Are the Poor to Live?: Transforming Public Housing Communities. New York: M.E. Sharpe, 2006.

Friedman, Milton. A Theory of the Consumption Function. Princeton, NJ: Princeton University Press, 1957.

Friedman, Joseph, and Daniel Weinberg. The Economics of Housing Vouchers. New York: Academic Press, 1982.

Friedman, Milton and Rose D. Friedman. Free to Choose: A Personal Statement. New York: Harcourt Brace Jovanovich, 1980.

Green, Richard and Stephen Malpezzi. A Primer on U.S. Housing Markets and Housing Policy. Washington, DC: Urban Institute Press, 2003.

Hunt, D. Bradford. Blueprint for Disaster: The Unraveling of Chicago Public Housing. Chicago: University of Chicago Press, 2009.

ICF Incorporated. Evaluation of the Low Income Housing Tax Credit. Washington, DC: Report to the U.S. Department of Housing and Urban Development, 1991.

Joint Center for Housing Studies of Harvard University. "The State of the Nation's Housing." Cambridge: Harvard University, 2013.

Malpezzi, Stephen and Richard Green. "What Has Happened to the Bottom of the U.S. Housing Market?” Urban Studies 33: 1807-1820, 1996.

Malpezzi, Stephen and Stephen Mayo. "Getting Housing Incentives Right: A Case Study of the Effects of Regulations, Taxes, and Subsidies in Housing Supply in Malaysia." Land Economics 73 (1997): 372-391.

Mayo, Stephen. "Sources of Inefficiency in Subsidized Housing Programs: A

Comparison of U.S. and German Experience." Journal of Urban Economics 20 (1986): 229-249.

McDonald, John. "Public Housing Construction and the Cities." Urban Studies Research (2011): 112.

McDonald, John F. and Daniel P. McMillen. Urban Economics and Real Estate: Theory and Policy. Hoboken, NJ: John Wiley \& Sons, 2011.

Quigley, John and Stephen Raphael. “Is Housing Unaffordable? Why Isn’t It More 


\section{Amps}

Affordable?" The Journal of Economic Perspectives 18 (2004): 191-214.

Steffen, Barry. "Worst Case Housing Needs 2011.” Report to Congress, U.S. Dept. of Housing and Urban Development, 2013.

Taylor, John. Getting Off Track: How Government Actions and Interventions Caused, Prolonged, and Worsened the Financial Crisis. Stanford, CA: Hoover Institution Press, 2009.

\footnotetext{
About the author.

John F. McDonald is emeritus professor of economics at the University of Illinois at Chicago. He earned the $\mathrm{PhD}$ in economics at Yale University in 1971, and is the author of ten books including Urban Economics and Real Estate, $2^{\text {nd }}$ ed., with Daniel McMillen (Wiley, 2011) and Postwar Urban America (Routledge, 2014). He is a fellow of the Regional Science Association International and was awarded the David Ricardo Medal by the American Real Estate Society in 2013.
} 